\title{
Emphasizing Concrete Representation to Enhance Students' Conceptual Understanding of Operations on Integers
}

\author{
Madihah Khalid $^{a}$ and Zulmaryan Embong ${ }^{\mathrm{b}}$ \\ ${ }^{a}$ International Islamic University, Malaysia (ORCID: 0000-0003-2798-3628) \\ ${ }^{\mathbf{b}}$ International Islamic University, Malaysia (ORCID: 0000-0002-5653-1631)
}

Article History: Received: 30 July 2020; Accepted: 3 November 2020; Published online: 9 December 2020

\begin{abstract}
This paper presents the findings of an intervention study that emphasizes concrete representation to improve students' conceptual understanding in learning mathematics. The study specifically examined the effectiveness of focusing on concrete representations - the algebra tiles, in minimizing students' errors in the operation on integers. A quasiexperimental design with a sample of 60 students from two intermediate Year 7 classes was employed in this study. The control group and the experimental group consisted of 30 students each, chosen through purposive sampling. Data from pre and post-tests and field notes were collected and analysed to measure changes from the intervention. The quantitative data from the tests showed an increase from 14.70 to 23.47 for the experimental group, as compared to 18.67 to 22.57 for the control group. The ANCOVA returns statistically significant results that can be attributed to the intervention strategies. Data from field notes indicate students' improvement in problem-solving skills, and students' interest in the lessons and motivation to learn. This study suggests that teaching with emphasis on concrete representation improves students' conceptual understanding. Hence students' understanding of integers was enhanced due to the promotion of concepts through manipulatives, pictures, verbal and symbolic representation which were also employed during the intervention. This study may be useful to teachers who usually encounter problems when teaching this topic.
\end{abstract}

Keywords: Algebra tiles, teaching and learning integers, intervention, multiple representation, manipulative

DOI: $10.16949 /$ turkbilmat. 775605

\section{Introduction}

Memorization of mathematics formulae and procedures, as well as manipulation of numbers without knowing the concepts or processes involved is popularly practiced by some students and encouraged by some teachers (Boaler, 2015). However, memorizing facts and mastering computation are not as valuable as having a deep knowledge of mathematical concepts and ideas, which result in surface understanding and lower performance in mathematics. In 2019, National Assessment of Educational Progress (NAEP) declared that only $41 \%$ of the grade 4 and $34 \%$ of the grade 8 pupils in USA were at the satisfactory proficient grade level in mathematics. At the same time, Ahn and Choi (2014) stated that among US high school students who graduated in 2012, only $44 \%$ were ready for college-level mathematics. In Malaysia, the declining performance in international assessment such as Trends in Mathematics and Science Studies (TIMSS) and Program for International Students Assessment (PISA) between1999 to 2015 has been a true concern. Although the Ministry of Education (2013) emphasizes 'Higher Order Thinking Skills' in the teaching and learning process, teachers are still not focussing on students' conceptual understanding (Khalid, 2017; Osman et al., 2018). In developing students' mathematics skills and interest in STEM related fields, the teaching and learning of STEM should deemphasize rote memorization and concentrate on students' understanding. This is important for Malaysia to remain competitive globally.

Mathematics is a subject that encompasses a variety of concepts and skills. Understanding mathematics concepts is important as it assists students to generalize from specific knowledge to deep and genuine understanding. Conceptual understanding focuses on knowing the connections between chunks of knowledge, besides organizing the knowledge in an orderly manner. It can also be deduced as "both knowing ideas in an interconnected and organized way and knowing more ideas along the novice-expert spectrum" (Meyer (2018) as quoted from National Research Council (2001, pp. 118-119). Hence, conceptual understanding is vital in learning mathematics. Rather than giving students rules and procedures to memorise, ask them to develop the solution by using their own creativity and critical thinking. Teachers should provide freedom in thinking to students, so that students can develop or construct their own knowledge. Group discussion, peer-teaching and collaborative learning can assist students to come up with solutions to many problems by means of new knowledge and understanding.

In teaching, teachers' use of multiple representation, such as manipulatives, pictures, verbal and written symbols, and real life situations helps students transform abstract problems into something concrete that is observable, imaginable and doable. Multiple representation approach is a successful way of teaching conceptual 
understanding in mathematics. Lesh (1979) illustrated that multiple representations of concepts can be utilised as a helping tool for pupils in order to develop deeper and more flexible understandings. He came up with a representation model of five different effective ways which are meaningful - manipulatives, powerful pictures, sensory spoken language, worldly written symbols and real-life situations, as illustrated in Figure 1. When students can piece ideas together through understanding the concepts, they develop the skills to see underlying patterns. However, to implement teaching that aims for conceptual understanding of mathematics requires teachers/ educators with such knowledge and skills. Some teachers prefer to teach procedures to get the right answers because it demands less time to complete the often extensive syllabus. Although teaching for understanding takes more time, 'it will have a positive effect, which builds on itself' (Korn, 2014, p. 9). This paper will present the findings from a research study that emphasizes students' conceptual understanding in learning integers by embedding multiple representations - focusing on concrete representation.

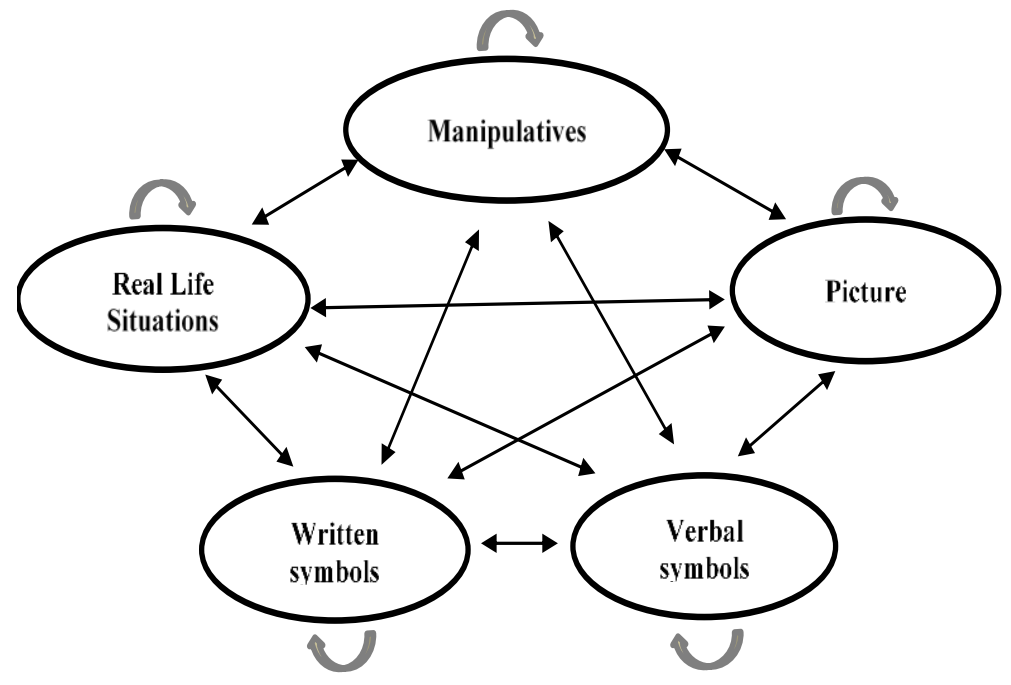

Figure 1. Lesh's (1979) Model of Multiple Representations

\subsection{Literature Review}

Research shows that students have difficulties in solving basic problems involving operations on integers, especially when it involves addition and subtraction (Khalid et al., 2018; Toh, Tengah, Shahrill, Tan \& Leong, 2017; Makonye \& Fakude, 2016; Schindler \& Hubman, 2013; Sadler, 2012; Widjaya, Stacey \& Steinle, 2011; Badarudin \& Khalid, 2009; 2008; Steiner, 2009; Hayes \& Stacey, 1999). One of the causes mentioned by Khalid and Embong (2020, p. 2) is due to "students being taught to follow rules and procedures in a very abstract manner without going through the models for better conceptual understanding". Many researches have been conducted to document students' errors and misconception, but only a few of the researches involved intervention study to lessen the errors and enhance students' understanding of integers (Fuadiah, Suryadi \& Turmudi, 2017; Makonye \& Fakude, 2016; Okpube, 2016). Consequently, this paper will relate the findings of a quasi-experimental research study that highlights multiple representations to enhance students' understanding of operations on integers. In this study, an intervention was conducted by emphasizing algebra tiles, which is a concrete representation, while not neglecting other representations. "Operations on integers" here means routine problems involving integers that are set up with the basic operations of addition (+), subtraction (-), multiplication $(\times)$ and division $(\div)$.

\subsubsection{Conceptual Understanding in Integers and Operations on Integers}

Students find understanding integers itself and solving problems involving operations on integers difficult and challenging (Fuadiah et al., 2017). The fact that the value of -17 is less than -12 is opposite to their belief when dealing with positive whole numbers. To understand this concept, students are required to build schemas and models that enable them to visualise the contrast and relationships between numbers. The subtraction operation, especially when the number is negative, is difficult for the students to comprehend. The notion of subtracting a negative number giving the same result as adding the opposite of negative numbers is difficult for many students to comprehend. When students have limited understanding of subtracting negative numbers, they may result to blindly following the rules. A study by Badarudin and Khalid (2009) found that when students were faced with the expression +2-(-6), many of them used the rule (according to them, since there are two negatives, then the answer will be positive) to work out the appropriate sign, operated with it (in this case adding 2 and 6), to get 8 . They might get the correct answer in this case, but not for some others such as in solving (-26) where the students would think 8 as the answer, according to their misapplied rules. Hayes and Stacey (1999) found similar incidences of students misapplying the rules, where 'two negatives make a positive' rule was 
applied to $(-4+-2)$ to get +6 . Teachers also need to be very careful of the language used when teaching integers. The word 'negative' should be used properly when they need to address negative numbers. The word 'minus' should be avoided. The use of the term 'minus' instead of 'negative' can confuse students between the sign and the operations.

Kuchemann (1981) stated that the use of the number line may also lead to students' confusion especially when a negative number is to be subtracted from another number. Number line is another abstract representation of abstract ideas. In developing mathematical concepts, students' understanding should be developed by linking the new concepts with known concepts and everyday experiences. From personal experience of Fuadiah, Suryadi and Turmudi (2017), students tend to be taught that adding two negative numbers will produce a negative answer but multiplying two negative numbers will result in a positive one. It is difficult for students to understand these concepts and the reason why the numbers behave that way. The difficulty in understanding the multiplication of negative numbers is due to the reason that it is not something that the students apply in their everyday lives. However, it is important for them to master the skills of adding, subtracting, multiplying and dividing integers which are fundamental in algebra. If students struggle at this stage and fail to master the skills, they will likely become more frustrated in facing more complicated and challenging topics. Fortunately, there are many ways to teach them the operations of integers. Some available strategies are able to help them master these vital skills, and simultaneously build their self confidence in doing mathematics. Yet, how can students master the skills without memorising? The key to a successful method is not to let them memorise a bunch of rules prior to understanding. Instead, students' understanding may be enhanced using pictures or handling manipulatives, to allow them to translate the concepts into images. One of the strategies is to apply concrete representation, and combining of a few other representations in a single teaching and learning process.

The use of algebra tiles is to mainly model the processes (usually of algebra concepts in mathematics) and also to help students visualise in order to conceptually understand the processes (Brahier, 2016). Other uses include the application to addition, subtraction, multiplication and division of integers; to complete the square; to factor expressions and to relay the distributive property (Leitze \& Kitt, 2000). Algebra tiles are effective manipulatives because they enable students to make sense of mathematical problems concretely (Heddens \& Speer, 2001 as cited in Saraswati, 2016, p. 24). Algebra tiles are the visual and hands-on way for students to explore algebraic expressions, where students can learn from their own experiences (Okpube, 2016). Thus, it is more meaningful compared to other models such as the number-line representation, which is less effective in solving problems related to multiplication and division of integers. To use algebra tiles, teachers need a small square which is yellow (or any colour to represent +1 ) on one side and red (another colour on the flip-side) which represents -1 which are additive inverses of each other as shown in Figure 2. The two colours represent a neutral or zero pair.

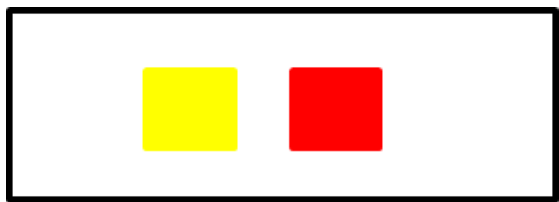

Figure 2. The Manipulative representing zero/neutral pair $(+1+(-1)=0)$

Hence, the problem $(+\mathbf{2})-(-\mathbf{4})=$ ? can be represented as in Figure 3 .

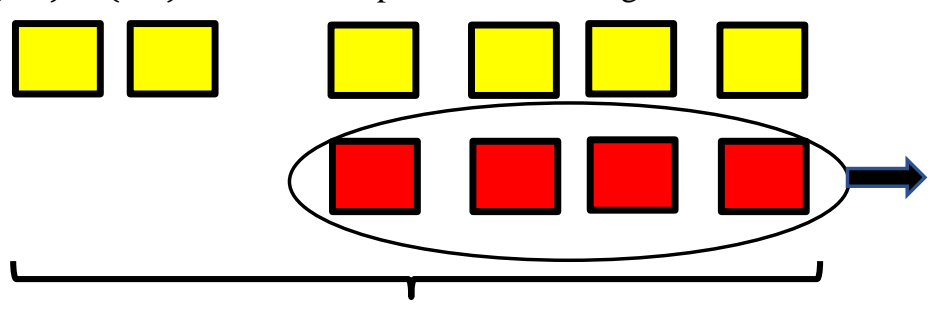

Add four zero pairs to +2 , and then take away four red tiles $(-4)$ from above to give six yellow tiles left. Therefore, $(+2)-(-4)=+6$

Figure 3. Using algebra tiles to solve $(+2)-(-4)$

\subsection{Objectives of the Study}

This study was conducted to examine the effect of teaching for conceptual understanding in the topic of operations on integers. In order to enhance students' understanding, this study tried to incorporate most of the representation for teaching mathematics as mentioned by Lesh, Post and Behr (1987), which are the verbal, pictures, real life, manipulatives and symbols. Manipulatives seems to be lacking in the lessons related to operations on integers and hence this is the focus of the research. Algebra tiles were used to help students make 
sense of the problems related to operations on integers. Other representations such as verbal and its connection to symbolic representation (for example emphasizing the difference between operations and signs) and pictorial representation (when students later draw pictures of the algebra tiles when solving problems) are also considered in the study. Consequently, the following research question was applied to guide the research: What is the impact of emphasizing concrete representations (the algebra tiles) on the students' performance in solving problems involving operation on integers?

\section{Method}

\subsection{Research Design and Procedure}

This research employs quasi-experimental design in investigating the impact of algebra tiles on students' affective change and performance on integers. Quasi-experimental design of the pretest-posttest control-group design was considered best when two non-equivalent groups were employed in the study (Creswell \& Creswell, 2017). Randomization of participants was not possible in this study since it would have disrupted the classes and students too much, hence two existing classes from the same level at the same school were taken as they were. Qualitative and quantitative data were collected before, during and after the intervention period to examine students' changes.

For three weeks of normal mathematics lessons, students in the experimental group were taught about integers using multiple representations especially the algebra tiles in order to improve their understanding of integers. For the control group, the school mathematics teacher was free to deliver the lesson as he normally does. The teacher was more familiar with the number line approach, so he implemented the approach. The experimental group was taught by one of the researchers who delivered the content of the lesson according to the lesson plans prepared by the researchers.

\subsection{Participants}

A government school in Terengganu was selected for the purpose of intervention through purposive sampling. This is a semi-urban school with several Form 1 (Year 7) classes. Two classes with similar class size, student composition and ability levels (based on previous mathematics test results - intermediate ability level) were selected. Internal threats of maturation and regression (Creswell \& Creswell, 2017) were addressed since the two classes were closest in terms of students' ability level, composition and age-group. One was randomly assigned as the experimental group while the other acted as a control group. The experimental group was taught by one of the researchers (who has limited teaching experience) while the control group was taught by the regular teacher with 10 years' experience. Other internal threats such as mortality and testing were also minimized since no student dropped out of the study and the researchers used the same test for pre and post-test except for the arrangement of the questions. Furthermore, the duration of 4 weeks between the tests was long enough for the students not to remember the responses. It is worth mentioning here that to avoid threats to external validity, this result cannot be generalised to other groups with different characteristics of participants or other settings.

There were sixty students involved in the intervention altogether and each class comprised 30 students. A total of 27 (45\%) students involved in this part of the study were male, while $33(55 \%)$ students were female. The respondents' distribution is summarised in Table 1.

Table 1. Profile of Respondents for the Intervention

\begin{tabular}{lcccc}
\hline & Total Student & & Frequency & Percentage (\%) \\
\hline Experimental group & 30 & Male & 12 & 20 \\
\cline { 3 - 5 } & & Female & 18 & 30 \\
\hline Control Group & 30 & Male & 15 & 25 \\
\cline { 3 - 5 } & & Female & 15 & 25 \\
\hline Grand total & 60 & & 60 & 100 \\
\hline
\end{tabular}

\subsection{Instrument}

In answering the research question, two instruments were used to obtain all the relevant data and information. First, a pencil-and-paper instrument (see Khalid et. al, 2018) was used to measure students' scores before and after the intervention. The instrument, referred as the Errors Identification Integer Test or EIIT, comprised 32 routine multiple-choice problems involving operations on integers. The EIIT that was administered was adapted from the instrument developed by Bny Rosmah (2006). Second, are the field-notes. During classroom observations, field notes were captured to record the changes observed in the students and also to document students' perceptions towards algebra tiles. The EIIT was validated by using the Rasch Model (Embong, 2020) and exhibited high validity. Meanwhile, field notes were validated through member checking, peer debriefing and triangulation (with two school teachers acting as neutral observers). 


\subsection{Teaching Episodes}

The teaching of the topics took three weeks to complete. The lessons were planned according to the social constructivist style of teaching and learning - by giving students the problem of the day. Students were put in groups of 5 so that they can collaborate in solving the problem of the day. The problems discussed in class were specially selected to mirror real-life context and were challenging or interesting enough to maintain the pupils' attention and commitment. An example is as follows:

A submarine was first seen at sea level. It then moves 12 metres below sea level before it suddenly moves up 5 metres. At what depth is the submarine located now? If it wants to be at sea level again, how far must it move?

During classes, even from the first meeting, the researcher tried to build a classroom environment suitable for problem solvers. Instead of the teacher giving the answers, many questions were asked to allow the students to think. They were encouraged to communicate so that the teacher was able to examine their thinking process. This skill will help pupils become better problem solvers. One of the best strategies is to focus on classroom activities that use hands-on materials. This is the role played by the algebra tiles.

The class started by showing the pupils the yellow and red tiles. When discussions begin, pupils were allowed to guess what the lesson will be about. After a while, the pupils started giving their opinion. They then explored by playing with the tiles. The pupils were then asked what would happen if two yellow tiles were added to two red tiles. Some pupils shouted "It cancelled out. It becomes zero!" After elaborating on the usage of algebra tiles, the researcher gave pupils the problem of the day. The pupils discussed among themselves and tried to find the solution using algebra tiles and drawing. The researcher continued to ask questions so that students relate between the drawings and the tiles and solve the problem together. For example, one group of pupils first drew the situation on a piece of paper, and were then asked to transform it to symbolic representation. Although some pupils already guessed the correct answer, they were then asked to represent the situation using the algebra tiles. From the symbolic form, they manipulated the tiles to figure out the solution and compared it with other groups. Students were encouraged to draw the tiles when there were not enough tiles to go around. They seemed to realize later that drawing the tiles also helped them visualize the problem better. The researcher was not keen on having correct answers, but emphasized understanding the concept of integers, basic operation and negative values.

After the first week, students seemed to realize that teachers were not there to solve problems for them, but to support them to solve the problems themselves. The researcher only acted as a guide because pupils learn best when they are active participants in a learning process. In the classroom, students were encouraged to discover creative ways to solve problems. They came up with a few strategies and approaches and in doing so, formed deeper conceptual understanding of the topic. When using algebra tiles, pupils are able to feel, touch and handle the teaching aid. Pupils' senses are stimulated as they touch the algebra tiles, move them about, rearrange them, and/or see them.

The class process continued for three weeks until the last operation which is division, was completed. The pupils do not need to depend on their calculators anymore. They are able to solve multiplication and division problems by using algebra tiles. Therefore, algebra tiles gave the pupils independence and at the same time helped pupils to transform an abstract concept to actual objects.

\section{Results}

\subsection{Students' achievement after intervention}

All students in both the experimental and the control groups responded to the EIIT again one month after the intervention was completed. The minimum possible score for the test is zero (0) while the maximum score is thirty-two (32). The difference in scores of the students were measured as indicators of the students' level of understanding and the knowledge gained on integers. The difference in scores would reasonably indicate the success of both teaching approaches. The scores are illustrated in Table 2.

Table 2. Pre and Post Mean Scores for Control and Experimental Groups

\begin{tabular}{llcccccc}
\hline & \multicolumn{3}{c}{ Control } & \multicolumn{3}{c}{ Experimental } \\
\hline & Mean & SD & No. & Mean & SD & N \\
\hline pretest_score & 18.67 & 4.936 & 30 & 14.70 & 3.897 & 30 \\
\cline { 2 - 8 } & posttest_score & 22.57 & 4.532 & 30 & 23.47 & 4.419 & 30 \\
\hline
\end{tabular}

The mean difference was found to be higher in the experimental group (mean difference $=8.77$ ) compared to the control group (mean difference $=3.90$ ). Table 3 presents the results of paired-sample t-test that was conducted to evaluate the effect of the number line approach and algebra tiles on achievement in operations on integers for the control and experimental groups respectively. Both groups exhibit a statistically significant 
difference between the scores in post-test and pre-test. Clearly, the overall results of the post-teaching tests were higher than the pre-teaching result.

Table 3. Paired-Sample Test for Control and Experimental Groups

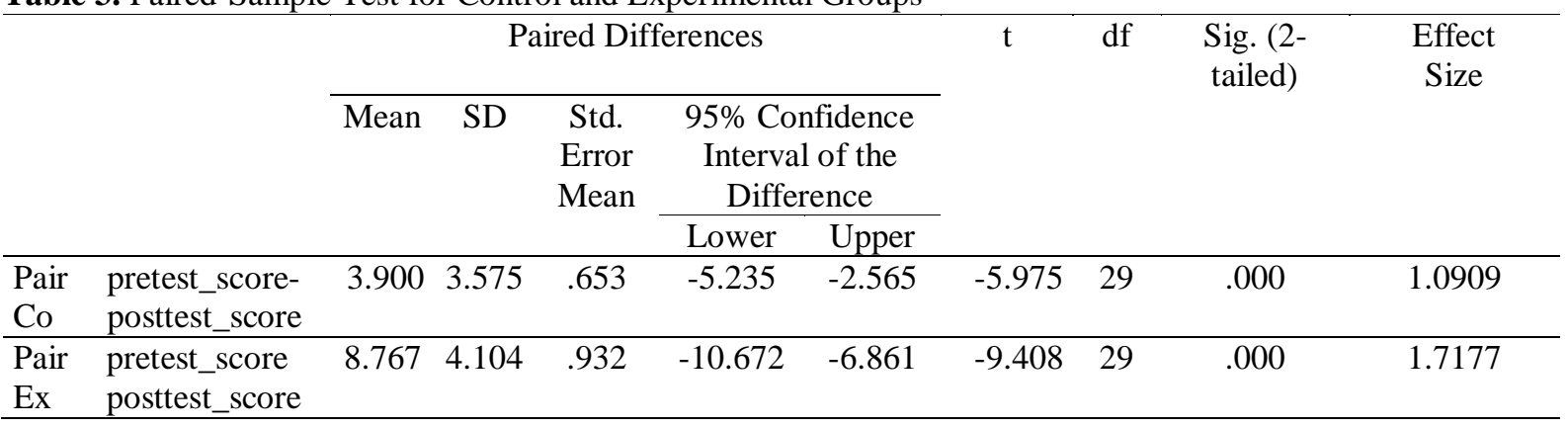

Next, Table 4 presents the comparison of post-test scores between the control and the experimental groups. Independent samples t-test between the post-tests from the groups also produced a significant result implying that the experimental group performed significantly better than the control group.

Table 4. Independent Samples Test

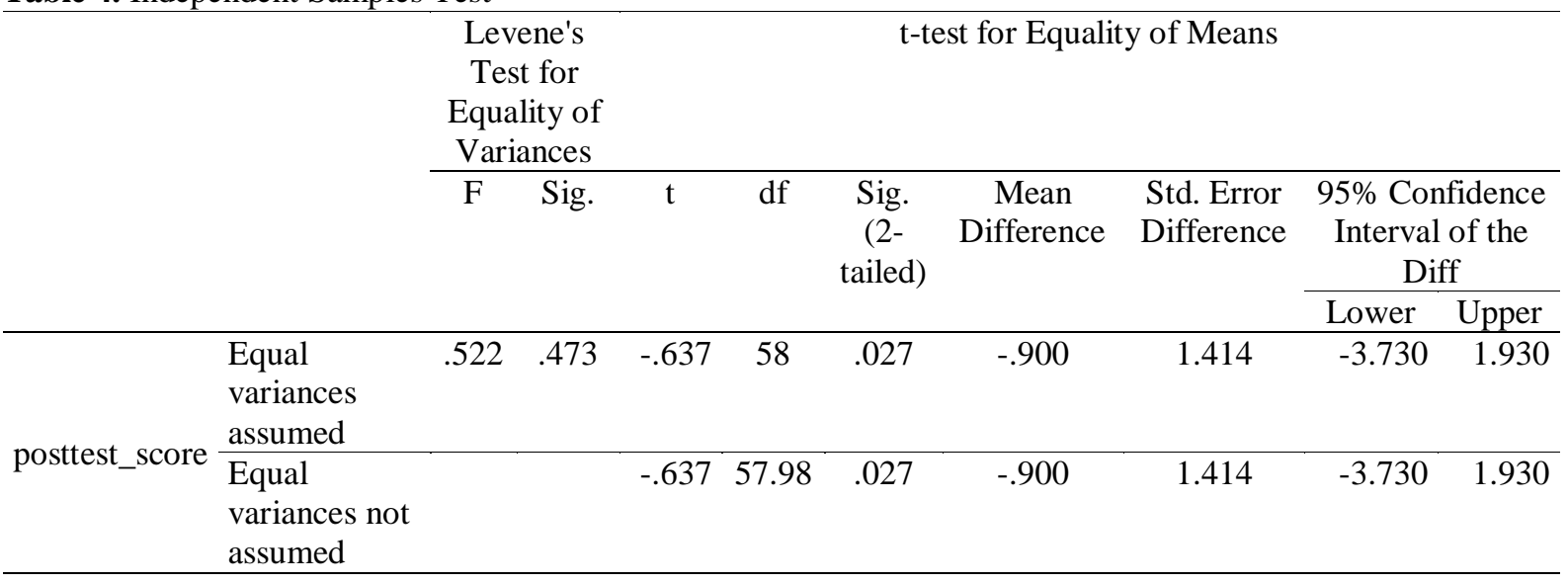

To strengthen the result from independent samples t-test, ANCOVA test was then conducted to determine whether the increase in score for the experimental group can be attributed to the intervention, by considering the pre-test result as the covariate. ANCOVA is utilized because the researchers wanted to remove the effects of some antecedent variable (in this case, the pretest results were used as covariates) to cater for effects of unequal grouping. Before the ANCOVA could be run, the data collected were examined whether they satisfy the required assumptions for one-way ANCOVA, to get a valid result.

Assumptions \#1 - \#5 for performing ANCOVA are satisfied by the data (Laerd Statistics, 2020). For this study, 1) both the covariate variable (pre-test result) and the dependent variable (post-test result) are measured on a continuous scale. 2) The independent variables meet the criterion of categorical and independence because 'group' (the experimental and control groups) is categorical and independent. 3) The control and experimental group pupils who participated in the study are from two different classes, hence they are independent. 4) There are no extreme outliers from the variable to be significant at $p<.001$. 5) Each category of the independent variables is normally distributed when checked with Shapiro-Wilks test

Assumption \#6 was assured since it was found that Levene's test for homogeneity of variance is not significant, implying acceptable differences (in terms of the groups' ability) of the pretest results. For Assumption \#7 checks if the covariate is linearly related to the dependent variable. Upon examination of the graphs from both data, it was found that the covariate and the post-test scores of the dependent variable and independent variable respectively are closely linear to each other because they are working in the same direction. Homoscedasticity of the covariate with respect to the post-test was satisfied for Assumption \#8, when tested in SPSS by plotting a scatterplot of the standardized residuals against the predicted values. 


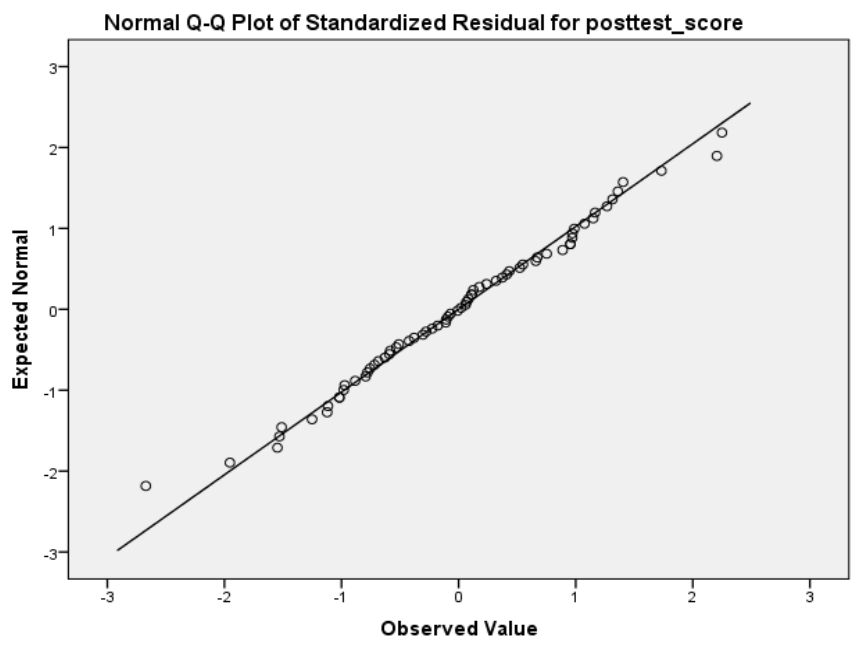

Figure 2. Standardized Residual for Posttest-Score

The graph obtained confirmed this statement since normality plot can be observed from the residual values, which is close with the diagonal line. Thus it can be contended that the data for this study show normality and equality of variance and satisfy the condition for performing the analysis of variance calculation. Lastly, for Assumption \#9 (the homogeneity of regression), it was found that the significant value for "group*pretest" is more than 0.05 (not significant), meaning that there is no interaction between the covariate and the independent variable. Table 5 shows that the significance value of the covariate by the dependent variable is $\mathrm{p}=.205$. Therefore, the assumption of homogeneity of regression slopes is tenable.

Table 5. Homogeneity of Regression

\section{Tests of Between-Subjects Effects}

Dependent Variable: posttest_score

\begin{tabular}{lrrrrr}
\hline Source & $\begin{array}{r}\text { Type III Sum of } \\
\text { Squares }\end{array}$ & df & Mean Square & F & Sig. \\
\hline Corrected Model & $764.700^{\mathrm{a}}$ & 3 & 254.900 & 9.633 & .000 \\
\hline Intercept & 533.599 & 1 & 533.599 & 20.165 & .000 \\
\hline group & 68.493 & 1 & 68.493 & 2.588 & .113 \\
\hline pretest_score & 651.283 & 1 & 651.283 & 24.612 & .000 \\
\hline group * pretest_score & 43.415 & 1 & 43.415 & 1.641 & .205 \\
\hline Error & 1693.579 & 64 & 26.462 & & \\
\hline Total & 38109.000 & 68 & & & \\
\hline Corrected Total & 2458.279 & 67 & & & \\
\hline
\end{tabular}

a. $\mathrm{R}$ Squared $=.311$ (Adjusted R Squared $=.279$ )

When the real ANCOVA test was run, the result shows that the Levene's test for homogeneity of post-test variance is non-significant (p>.05 as in Table 6), indicating that the group variance is not different (hence the assumption of homogeneity of variance is not violated).

Table 6. Levene's Test of Equality of Error Variances

\begin{tabular}{ccccc}
\hline \multicolumn{5}{c}{ Levene's Test of Equality of Error Variances $^{\mathbf{a}}$} \\
\hline Dependent Variable: & posttest_score & df 2 & Sig. \\
\hline F & df1 & 58 & .051 \\
\hline 4.061 & 1 & .
\end{tabular}

Tests the null hypothesis that the error variance of the dependent variable is equal across groups.

a. Design: Intercept + pretest_score + group

Table 7 shows that there is a significant difference $[\mathrm{F}(2,58)=10.362, \mathrm{p}=0.002]$ between the two post-test results. Hence, the ANCOVA result shows that the group learning with the algebra tiles produced a significantly better result than the number line method. 
Table 7. Tests of Between-Subjects Effects

\begin{tabular}{lcccccc}
\hline \multicolumn{7}{c}{ Tests of Between-Subjects Effects } \\
\hline Dependent Variable: & posttest_score & & & & \\
\hline Source & $\begin{array}{c}\text { Type III Sum of } \\
\text { Squares }\end{array}$ & Df & Mean Square & F & Sig. & $\begin{array}{c}\text { Partial Eta } \\
\text { Squared }\end{array}$ \\
\hline Corrected Model & $687.118^{\text {a }}$ & 2 & 343.559 & 18.407 & .000 & .392 \\
\hline Intercept & 402.632 & 1 & 402.632 & 21.572 & .000 & .275 \\
\hline pretest_score & 674.968 & 1 & 674.968 & 36.164 & .000 & .388 \\
\hline group & 193.403 & 1 & 193.403 & 10.362 & .002 & .154 \\
\hline Error & 1063.866 & 57 & 18.664 & & & \\
\hline Total & 33537.000 & 60 & & & & \\
\hline Corrected Total & 1750.983 & 59 & & & &
\end{tabular}

a. R Squared $=.392$ (Adjusted R Squared $=.371$ )

\subsection{Discussion on Pupils' Responses towards Algebra Tiles}

The researcher keeps field notes of what transpired in class during the intervention period of using algebraic tiles on the experimental group. From the field notes data, the researcher analyses for emerging themes related to the use of algebra tiles to supplement the quantitative result and found the following three elements shown by pupils during the three weeks of lessons, namely algebra tiles promotes problem solving, is fun to use and is motivating, as illustrated in Table 8.

Table 8. Emerging themes from Field notes

\begin{tabular}{|c|c|}
\hline Main Themes & Sub Themes \\
\hline Algebra tiles promotes problem solving & $\begin{array}{ll}\text { - } & \text { Active participation } \\
\text { - } & \text { Collaboration } \\
\text { - } & \text { Creative and critical thinking } \\
\text { - } & \text { Confidence }\end{array}$ \\
\hline Algebra tiles is fun to use & $\begin{array}{ll}- & \text { Explore and play with tiles } \\
\text { - } & \text { Interesting and fun class } \\
\end{array}$ \\
\hline Algebra tiles is motivating & $\begin{array}{ll}\text { - } & \text { Stimulate discussion } \\
\text { - } & \text { Influence learning because can see in reality } \\
\text { - } & \text { Provoke feeling of wanting to solve more } \\
\text { - } & \text { More interest in what friends are doing } \\
\end{array}$ \\
\hline
\end{tabular}

\subsubsection{Promotes Problem Solving}

From the field notes, one of the foremost elements noted was the enhancement of the pupils' problem solving skills with the help of algebra tiles. Knowledge seemed to be constructed because they were given the opportunity to explore, examine, query, note, collaborate, and talk about what they discovered. Hence, the use of the algebra tiles promotes other elements considered important in learning such as collaboration, creative and critical thinking, and active learning. When pupils were given algebra tiles as the manipulative in learning integers, they actively used the tiles as a tool in solving the problems set in the class. They gain confidence through manipulating the tiles. It is the beginning of getting a sense of structure, and that the structure eventually emerges in the form of generalization or expression. The use of algebra tiles enables the pupils to make sense of integers. Their use enable pupils to acquire knowledge, help in making the discovery created in their minds and hence enhance their performance. Learning eventually happened when pupils relate what they learn from one representation to another. They were able to use their creative and critical thinking and interrelate the different representations through active participation. The collaborative environment created by the teacher generates confidence and hence they were able to solve many of the problems given. This is mainly due to being able to see and manipulate the object (algebra tiles) given to them.

The use of algebra tiles helped pupils in dealing with the mathematical problems, as the researcher can hear sentences such as "Oh, I see", "I think I can remember this well because I can see what is going on when I use these tiles", "I easily understand what I have done with the algebra tiles" and "This lesson makes me want to solve more problems" expressed by a few pupils in the class. Pupils who used algebra tiles seem clearer with their method in solving the problem compared to their pre-test answers found in Table 9. 
Table 9. Algebra Tiles in Problem Solving

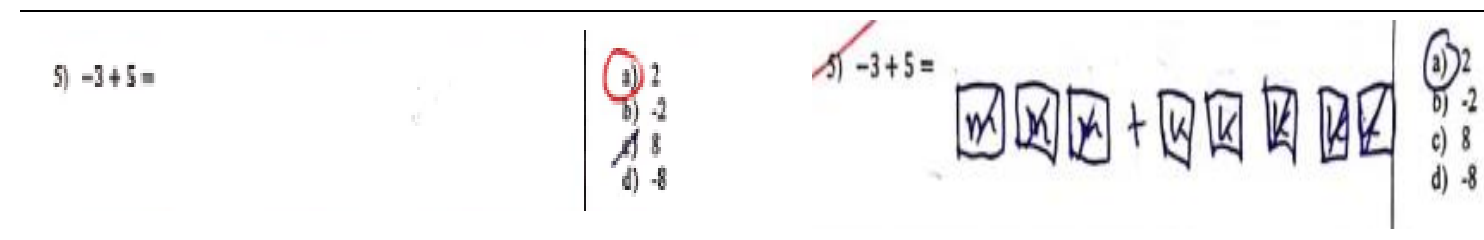

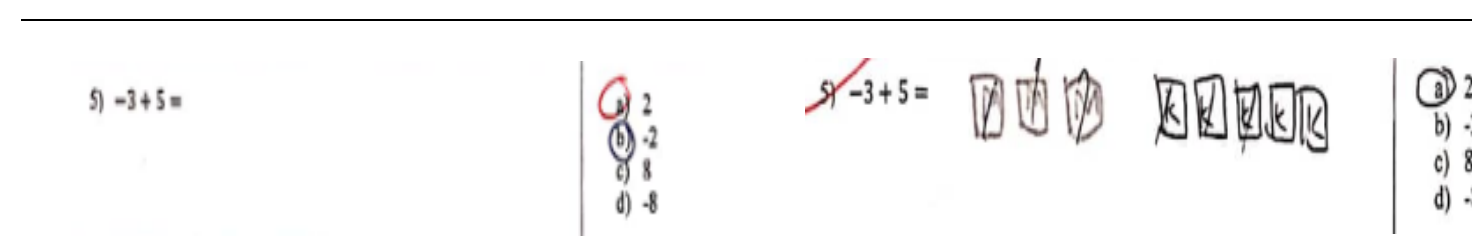

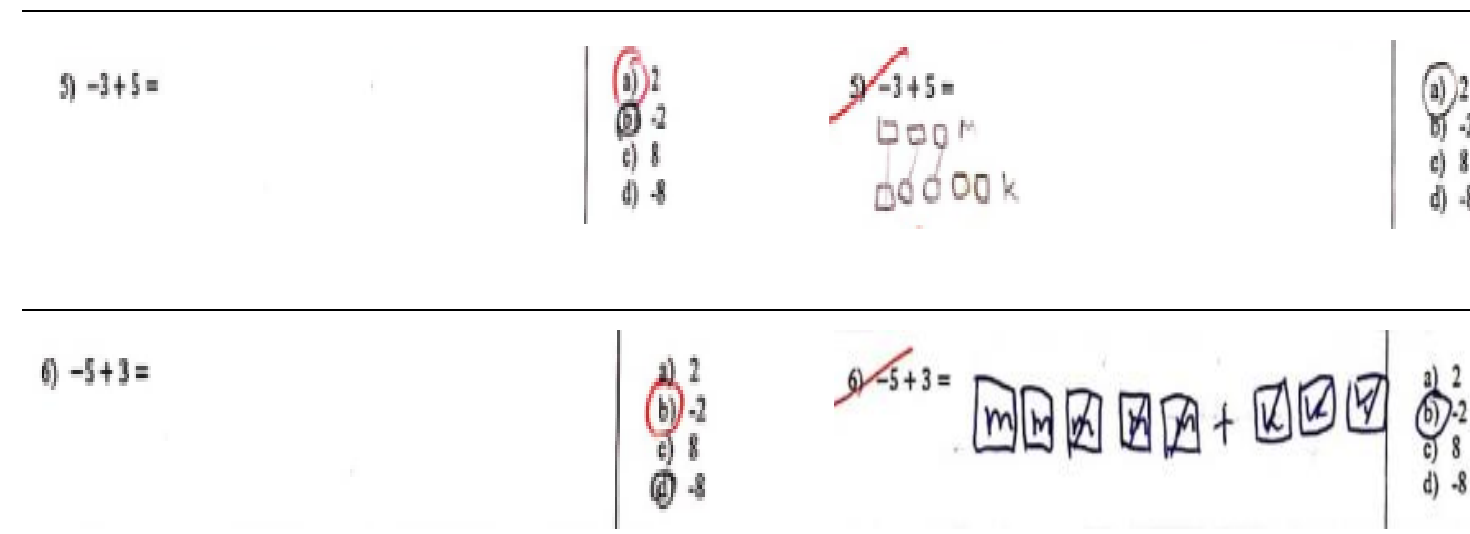

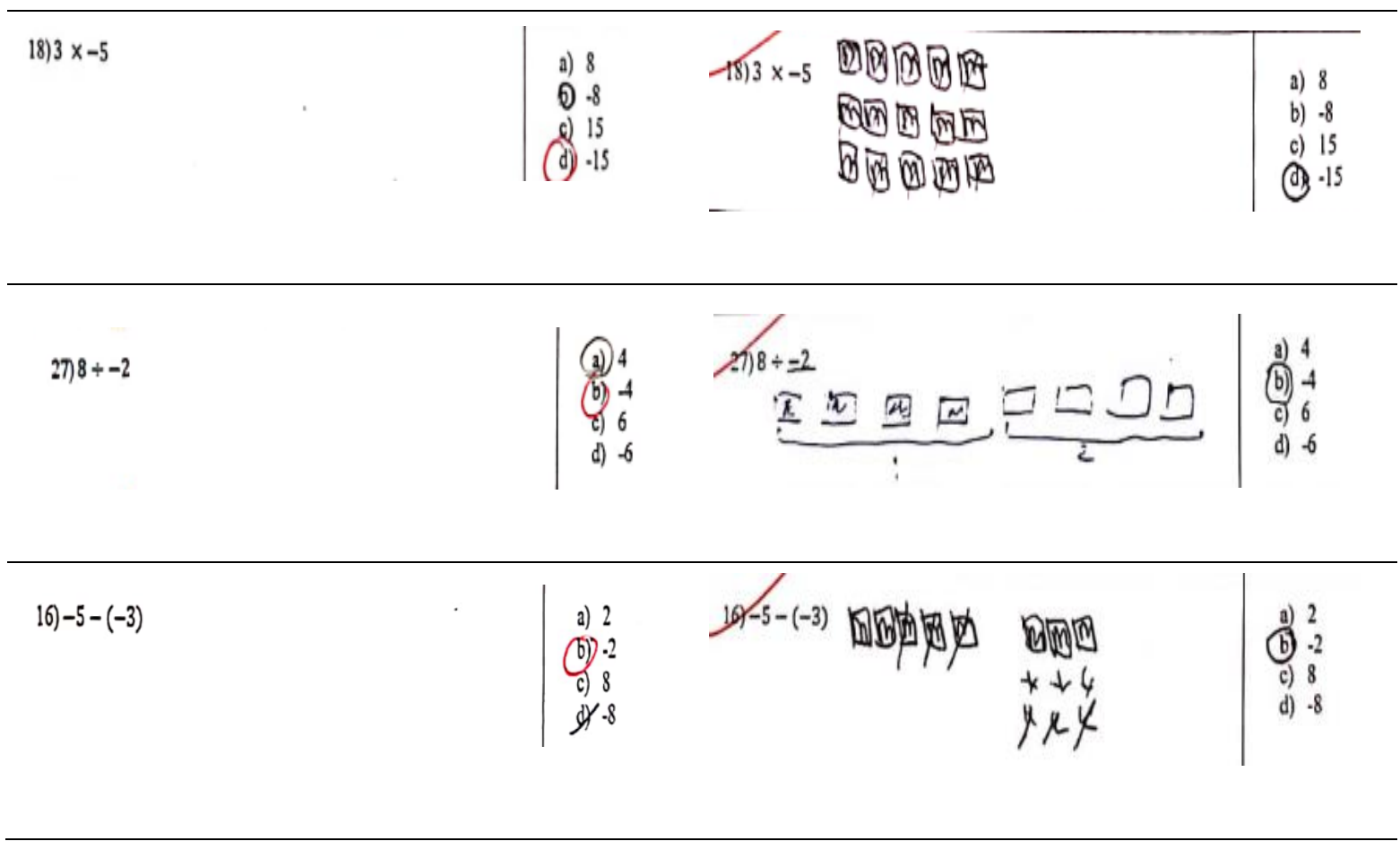

\subsubsection{Fun to Use}

Pupils also prefer to use algebra tiles because they are fun to use. From observations, it seemed clear that by providing pupils with the opportunity to explore 'real' objects, they seemed to enjoy learning integers. When 
asked what they would like to learn at the beginning of the second intervention lesson, they replied that they want to play with the tiles like yesterday. The pupils also agreed when one of the researchers (who taught the intervention lesson) further asked if they had fun yesterday.

Before the end of class, the researcher informally asked the pupils their thoughts on the algebra tiles. Majority of the pupils agreed that using the algebra tiles can attract their attention on teaching and learning integers. In addition, some say that algebra tiles could assist them to see beyond the signs and numbers. New mathematical concepts are built because such an approach allows them to see the abstract ideas in actual things and at the same time apply the concepts into their daily life activities. Furthermore, half of the class said that they were able to learn better when the teachers used actual aids during the lesson. Lastly, most of them agreed that algebra tiles make the learning process more interesting due to the attractiveness of the algebra tiles. Therefore, from the informal discussion, it shows that the pupils are getting pleasure from using tiles in solving integers.

\subsubsection{Motivating}

Lastly, another element of using the algebra tiles is that it enhances pupils' motivation to learn. Pupils feel motivated after learning integers using algebra tiles. The use of the algebra tiles also arouses pupils' interest and promotes active involvement in the lesson. Algebra tiles enhances pupils' performance because pupils are allowed to manipulate concrete objects to model, and reflect on the abstract concepts. Moreover, algebra tiles not only let pupils build their own schemas and models for mathematical ideas that are abstract, they also offer mutual ground to convey these ideas and models to their teacher and other members of the class. Pupils also seemed interested in how their friends are performing.

In addition, using algebra tiles is equally valuable for those pupils in need of remediation. Some of the weaker pupils in the classroom who have developed misconceptions or misunderstandings about operations on integers seemed to be more interested in handling the manipulatives and paid attention when the researcher explained how to neutralise the tiles for example. Allowing these pupils to use algebra tiles gives them an opportunity to re-build the necessary conceptual foundations. Algebra tiles are also valuable tools for advanced students, although they do not seem as motivating for the weaker pupils.

Before the lesson ends, the researcher informally asked the pupils what they gained from using algebra tiles. Majority of the pupils agreed that algebra tiles motivate them to learn mathematics better. 18 students said that algebra tiles motivate them to learn to solve more problems. Most of them agreed that algebra tiles give them a better understanding when they have an overall picture of the problems before they started to solve the questions. Therefore, it shows that algebra tiles also encourage pupils to obtain self-confidence in solving the integer problems.

\section{Conclusion and Implication for Future Study}

When the mean scores of the two intermediate classes were compared, the t-test results showed that they were statistically significant in terms of mean differences between the experimental and control groups of the post-test scores. Hence, using algebra tiles in the operations of integers seemed to lead to significantly better results than normal instruction. In addition, higher mean score from the experimental group compared to the control group, imply a significant effect from the intervention. The result for integers achievement from this study seemed to contradict the research results conducted by Sharp (1995) and Schlosser (2010) who found that algebra tiles did not influence the teaching and learning of integers.

Moreover, the data also show that algebra tiles encourage the teachers to design new activities in designing fun and motivating teaching and learning. Teachers should take learning as an active process in which the students use hands-on experiences to construct new mathematical concepts and relate them to the real life. Algebra tiles promotes the students to make an attempt to transform abstract fact to perceptible and sensible understanding using image and manipulatives so that they can obtain a deeper understanding on the subject concerned. This finding is parallel with Moses's (1977) since the algebra tiles have helped to design the attractive learning process.

In addition, this study also found that the algebra tiles inspired the students in problem solving. Therefore, students should be taught the systematic techniques to find the solution for any given mathematical problem. Problem solving is not only practical on similar questions, but also for developing new ideas and skills. Thus, by using algebra tiles, it gives students a chance of finding the potential solution. By working on a problem, students will become more enthusiastic to engage with various mathematical problems. This finding is parallel with Thorthon (2001) who states that visual approach is able to promote problem solving environment in the classroom.

Lastly, the study also found that the level of motivation among the students increased after using algebra tiles. In the development of new understanding, students need a systematic instruction and they have to make 
connections between mathematical concepts and real world using actual objects. Diagrams, graphs, and pictures could support the teachers to represent the mathematical concepts in the most interesting ways. This finding is parallel with Stokes (2002) who states that the algebra tiles are able to motivate students in the process of understanding the mathematical concepts.

Therefore, the analysis indicates that algebra tiles could assist students to score better and minimise their errors in their post-test. Following the intervention, the students were able to solve mathematical problems properly. Albeit the researcher's own lack of time in explaining integers through algebra tiles, this result is highly suggestive that the normal teacher can use this method in teaching integers to minimise students' errors. Consequently, the result shows that algebra tiles are beneficial to assist students' thorough understanding of mathematical concepts since the mean shows that algebra tiles had a higher score compared to the traditional method.

Suggestions for future studies would be to include more clinical interviews with students and teachers in order to investigate in depth on how students and teachers feel about the use of manipulatives such as algebra tiles for conceptual understanding of mathematics. It is stated in Khalid and Embong (2020) that teachers usually apply verbal and go straight to symbolic representation because of time constraint, and tend to neglect other representations especially concrete representation. This study highlights the importance of multiple representation and hence the researchers would like to stress that in teaching for conceptual understanding, they cannot be ignored.

Acknowledgement. This research was supported by [FRGS/1/2016/SSI09/UIAM/02/10]. We would like to thank the Ministry of Education for providing us with the grant and make this research possible.

\section{References}

Ahn, S., \& Choi, J. (2014, April). A synthesis of the quantitative literature on students' mathematics achievement. Paper presented at the American Educational Research Association, San Diego, CA.

Badarudin, B. R., \& Khalid, M. (2008). Using the Jar Model to Improve Students' Understanding of Operations on Integers. In B. Gomez., D. De Bock, \& Z. Usiskin (Eds), Proceedings of ICME-11-topic study group 10 research and development in the teaching and learning of number systems and arithmetic (Vol. 1, pp. 85-94) ICME Mexico.

Badarudin, B. R., \& Khalid, M. (2009). Investigating students' common errors in integers. In: Boorer, D., Perera Q., Wooed, K. (Eds.) Evolving pedagogies: Meeting the global challenges of diversity and interdependence (pp. 233 - 250). Brunei: Universiti Brunei Darussalam Press.

Bny Rosmah, B. (2006). Investigating Teaching and Learning of Integers at Form 1 level in Brunei Darussalam. (Unpublished Master thesis). University of Brunei Darussalam, Brunei.

Boaler, J. (2015). What's math got to do with it?: How teachers and parents can transform mathematics learning and inspire success. Penguin Books.

Brahier, D. J. (2016). Teaching secondary and middle school mathematics. New York: Routledge

Creswell, J. W., \& Creswell, J. D., (2017). Design Approach: Qualitative, quantitative and mixed-methods approaches $\left(5^{\text {th }}\right.$ ed.). Singapore: Sage Publication.

Embong, Z. (2020). Analysing pupils' errors in operations of integers among form 1 pupil. (Unpublished Doctora dissertation). IIUM, Malaysia.

Fuadiah, N. F., Suryadi, D. \& Turmudi. (2017). Some difficulties in understanding negative numbers faced by students: A qualitative study applied at secondary schools in Indonesia. International Education Studies; 10(1), 24-38. https://doi.org/10.5539/ies.v10n1p24

Hayes, B. \& Stacey, K. (1999, July). Teaching negative number using integer tiles. In J. M. Truran \& K. M. Truran (Eds.), Making the difference In Proceedings of the 22nd annual conference of the mathematics education research group of Australasia (MERGA, p.573), Adelaide, Australia.

Khalid, M., \& Embong, Z. (2020). Sources and possible causes of errors and misconceptions in operations of integers. International Electronic Journal of Mathematics Education, 15(2), em0568.

Khalid, M., Ibrahim, M. B., Saad, S., Othman, J., Mohd Yussuf, Y., Embong, Z., (2018, November). A preliminary study on form 1 students errors and misconception in operations of integers. In R. Embong, H.M. Lateh (Eds) Proceeding of National Education Deans' Council Seminar (pp. 115 - 124), UNISZA, Malaysia.

Khalid, M (2017). Fostering problem solving and performance assessment among Malaysian mathematics teachers. Sains Humanika, 9, (1-2).

Korn, J. (2014). Teaching conceptual understanding of mathematics via a hands-on approach. (Unpublished Senior Honours Thesis). Liberty University, USA.

Kuchemann, D. E. (1981) Algebra.In K.M. Hart (Ed) Children's understanding of mathematics: 11-16 (pp. 102 119). London: John Murray. 
Laerd Statistics (2020). One way ANCOVA in SPSS statistics. Retrieved from https://statistics.laerd.com/spsstutorials/ancova-using-spss-statistics.php

Leitze, A. R., \& Kitt, N. A. (2000). Using homemade algebra tiles to develop algebra and pre-algebra concepts. Mathematics Teacher, 93(6), 462-520.

Lesh, R. (1979). Mathematical learning disabilities: considerations for identification, diagnosis and remediation. In R. Lesh, D. Mierkiewicz, \& M.G. Kantowski (Eds), Applied mathematical problem solving (pp. 235-264). Ohio: ERIC/SMEAC.

Lesh, R., Post, T., \& Behr, M. (1987). Representations and translations among representations in mathematics learning and problem solving. Teaching and Learning of Mathematics, 21, 33-40.

Makonye, J. P., \& Fakude, J. (2016). A study of errors and misconceptions in the learning of addition and subtraction of directed numbers in grade 8. SAGE Open, 6(4), 2158244016671375.

Meyer, D. (2018, October). "What does fluency without understanding look like?" Retrieved from https://blog.mrmeyer.com/2018/what-does-fluency-without-understanding-look-like/

Moses, B. E. (1977). The nature of spatial ability and its relationship to mathematical problem solving. (Unpublished doctoral dissertation). Indiana University: USA.

National Assessment of Educational Progress [NAEP]. (2019). 2019 Mathematics Assessment, Institute of Education Sciences, National Center for Education Statistics, U.S. Department of Education.

National Research Council. (2001). Adding it up: Helping children learn mathematics. In Kilpatrick, J. Swafford, \& B. Findell (Eds.). Washington, DC: National Academy Press.

Okpube, N. M. (2016). Card games and algebra tic tacmatics on achievement of junior Secondary II students in algebraic expressions. International Journal of Evaluation and Research in Education, 5(2), 93-100. DOI: http://doi.org/10.11591/ijere.v5i2.4527

Osman, S., Che Yang, C. N. A., Abu, M. S., Ismail, N., Jambari, H., \& Kumar, J. A. (2018). Enhancing students' mathematical problem-solving skills through bar model visualisation technique. International Electronic Journal of Mathematics Education, 13(3), 273-279. https://doi.org/10.12973/iejme/3919

Sadler, J. T. (2012). The positives about negatives: A study of errors and misconceptions with integer operations in adult education (Unpublished master's thesis). State University of New York.

Saraswati, S. (2016). Supporting students' understanding of linear equations with one variable using algebra tiles. Journal on Mathematics Education, 7(1), 21-32. DOI: 10.22342/jme.7.1.2814.19-30

Schindler, M., \& Hubmann, S. (2013). About Student's individual concepts of negative integer: in terms of the order relation. In B. Ubuz, C. Hacer, \& M.A. Mariotti, (Eds.), Proceedings of the Eighth Congress of the European Society for Research in Mathematics Education (pp. 373-382). Ankara, Turkey: ERME and METU.

Schlosser, T. K. (2010). Using algebra tiles to aid students in factoring polynomials (Unpublished master's thesis). Central Connecticut State University, New Britain.

Sharp, J. M. (1995, October). Results of using algebra tiles as meaningful representations of algebra concepts. Paper presented at the Annual Meeting of the Mid-Western Education Research Association, Chicago.

Steiner, C. J. (2009). A study of pre-service elementary teachers' conceptual understanding of integers (Unpublished doctoral dissertation). Kent State University College and Graduate School of Education, US.

Stokes, S. (2002). Visual literacy in teaching and learning: a literature perspective. Electronic Journal for the Integration of Technology in Education, 1(1), 10-19.

Thornton, S. (2001). A picture is worth a thousand words. Retrieved February 15, 2017 from math.unipa.it/ grim/AThornton251.PDF

Toh, T.S., Tengah, K.A., Shahrill, M., Tan, A. \& Leong, E. (2017, April). The flipped classroom strategy: The effects of implementation at the elementary school level mathematics lessons. In Proceeding of the 3rd International Conference on Education 2017 (ICEDU 2017), (pp. 186-197) Kuala Lumpur, Malaysia.

Widjaja, W., Stacey, K., \& Steinle, V. (2011). Locating negative decimals on the number line: Insights into the thinking of pre-service primary teachers. Journal of Mathematical Behavior, 30(1), 80-91. https://doi.org/10.1016/j.mathb.2010.11.004. 